\title{
Prevention of stent thrombosis: challenges and solutions
}

This article was published in the following Dove Press journal:

Vascular Health and Risk Management

27 January 2015

Number of times this article has been viewed

\section{Risheen Reejhsinghani \\ Amir S Lotfi}

Division of Cardiology, Baystate Medical Center, Springfield, MA, USA
Correspondence: Amir S Lotfi

Division of Cardiology, Baystate Medical Center, 759 Chestnut Street, Springfield, MA OII99, USA

Email amir.lotfi@bhs.org
Abstract: Stent thrombosis is an uncommon but serious complication which carries with it significant mortality and morbidity. This review analyzes the entity of stent thrombosis from a historical and clinical perspective, and chronicles the evolution of this condition through the various generations of stent development, from bare metal to first-generation, second-generation, and third-generation drug-eluting stents. It also delineates the specific risk factors associated with stent thrombosis and comprehensively examines the literature related to each of these risks. Finally, it highlights the preventative strategies that can be garnered from the existing data, and concludes that a multifactorial approach is necessary to combat the occurrence of stent thrombosis, with higher risk groups, such as patients with ST segment elevation myocardial infarction, meriting further research.

Keywords: stent thrombosis, preventative strategies, post-procedural myocardial infarction

\section{Introduction}

Coronary artery disease has had a tremendous impact on global health. Jacques Puel of Toulouse, France, implanted the first human coronary stent, a self-expanding stainless steel Wallstent, in 1986. ${ }^{1}$ However, the use of coronary endoprostheses did not become routine in the US until the 1990s, after the Palmaz-Schatz stent was approved in 1994, heralding a new era in the treatment of coronary artery disease.

The bare metal stent (BMS) decreased restenosis and acute occlusion rates when compared with balloon angioplasty. With the subsequent increase in use of stents during percutaneous coronary intervention (PCI), the focus of treatment evolved from procedural success to prevention of in-stent restenosis. The drug-eluting stent (DES) was added to the armamentarium in clinical practice to reduce BMS restenosis rates. However, the initial enthusiasm was tempered by concerns regarding an increased risk of late stent thrombosis (LST) and very late stent thrombosis (VLST).

Stent thrombosis is a serious event resulting from occlusion of the endoprosthetic lumen by thrombus and is an entity with a wide chronological spectrum that can occur anywhere from intraprocedurally to years after implantation. Large volumes of literature have been devoted to stent thrombosis, with research that spans the entire spectrum of epidemiologic exploration. Many of the larger trials have resulted in evidence that we now take for granted in our daily practice, while others have provided the impetus to create newer and improved stents.

With the wealth of literature available, deconstructing the basic tenets of stent thrombosis can be somewhat daunting. This review summarizes the salient features 
of this condition, with a focus on the pertinent literature that has sculpted our current insights and understanding regarding stent thrombosis.

\section{Classification of stent thrombosis}

The Academic Research Consortium ${ }^{2}$ (ARC) is an informal collaboration between academic research organizations in the US and Europe. In 2006, the ARC held two meetings with the primary goal of creating consensus end point definitions for DES evaluations. Their aim was to establish consistent definitions across which trials of DES could be compared.

The ARC therefore proposed two distinct classifications ${ }^{2}$ of stent thrombosis incorporating both levels of evidence as well as timing of events, further stratified to define varying degrees of certainty and to imply different pathophysiological mechanisms, respectively. These classifications are summarized in Tables 1 and 2.

Four years later, a study performed by Cutlip et $\mathrm{al}^{3}$ was published. This study recognized that although the ARC criteria for classification of stent thrombosis were widely accepted, there was no validation of their sensitivity and specificity against autopsy data. Hence an autopsy registry of 139 subjects with prior coronary stenting was subjected to detailed histopathological analysis to assess for stent thrombosis.

The results of the study by Cutlip et al showed that specificity was high for definite (99\%) and definite plus probable $(83 \%)$ criteria, but the sensitivity was poor at $18 \%$ and $51 \%$, respectively. This group concluded that restricting ARC definitions to definite or definite plus probable stent thrombosis had resulted in substantial underreporting of true positive cases that were confirmed in their selected autopsy sample.

\section{Rates of stent thrombosis}

Stent thrombosis is one of the most serious complications of PCI, so its incidence and prevalence has been followed very

Table I Academic Research Consortium classification of stent thrombosis based on timing of events

\begin{tabular}{ll}
\hline Acute stent thrombosis* & $\begin{array}{l}0-24 \text { hours after stent } \\
\text { implantation }\end{array}$ \\
Subacute stent thrombosis* & $\begin{array}{l}24 \text { hours to } 30 \text { days after stent } \\
\text { implantation }\end{array}$ \\
Late stent thrombosis & 30 days to one year after stent \\
implantation
\end{tabular}

Note: *The term "early stent thrombosis" can be used to supplant acute and subacute stent thrombosis, according to the original Academic Research Consortium document. Copyright (C) 2007. Cutlip DE, Windecker S, Mehran R, et al. Academic Research Consortium. Academic Research Consortium clinical end points in coronary stent trials: a case for standardized definitions. Circulation. 2007; I 15:2344-235।. ${ }^{2}$
Table 2 "Trilevel of Certainty" classification of stent thrombosis proposed by the Academic Research Consortium

Definite stent thrombosis: angiographic confirmation of stent thrombosis

Presence of a thrombus that originates in the stent or in the segment $5 \mathrm{~mm}$ proximal or distal to the stent and presence of at least one of the following criteria within a 48-hour time window:

- Acute onset of ischemic symptoms at rest

- New ischemic electrocardiographic changes that suggest acute ischemia

- Typical rise and fall in cardiac biomarkers

- Nonocclusive thrombus

- Intracoronary thrombus

- Occlusive thrombus

- TIMI 0 or TIMI I intrastent or proximal to a stent up to the most adjacent proximal side branch or main branch

Definite stent thrombosis: pathological confirmation of stent thrombosis

Evidence of recent thrombus within the stent determined at autopsy or via examination of tissue retrieved following thrombectomy

Probable stent thrombosis

Considered to have occurred after intracoronary stenting in the following cases:

- Any unexplained death within the first 30 days

- Irrespective of the time after the index procedure, any myocardial infarction that is related to documented acute ischemia in the territory of the implanted stent without angiographic confirmation of stent thrombosis and in the absence of any other obvious cause Possible stent thrombosis

Considered to have occurred with any unexplained death from 30 days after intracoronary stenting until end of trial follow-up

Note: Copyright (C) 2007. Cutlip DE, Windecker S, Mehran R, et al. Academic Research Consortium. Academic Research Consortium clinical end points in coronary stent trials: a case for standardized definitions. Circulation. 2007;1 15:2344-2351.2 Abbreviation: TIMI, thrombolysis in myocardial infarction.

closely. The rates of stent thrombosis have also paralleled the evolution of improved stents and antiplatelet agents. Although there is much debate about whether randomized controlled trials accurately reflect "real-world" data applicable in clinical practice, there is abundant registry data and large observational studies to supplement the more traditional clinical trials.

The majority of stent thrombosis occurs within the first 30 days after PCI. In general clinical practice, the expected rate of early stent thrombosis is $\sim 1 \%$, and beyond 30 days is $0.2 \%-0.6 \%$ per year. ${ }^{4}$ For first-generation DES, LST occurs steadily at an annual rate of $0.4 \%-0.6 \%$ for up to 4 years. ${ }^{5}$ The incidence of LST and VLST in patients with BMS has been poorly characterized. A retrospective analysis of 4,503 patients treated with at least one BMS indicated the cumulative incidence of stent thrombosis at 10 years to be $2 \%{ }^{6}$ Table 3 depicts the rates of stent thrombosis by stent type as well as clinical presentation of coronary artery disease.

The incidence of definite or probable stent thrombosis also differs by the type of stent. In a meta-analysis of 
Table 3 Risk of early stent thrombosis according to clinical presentation

\begin{tabular}{llll}
\hline & Stable Angina & UA/NSTEMI & STEMI \\
\hline Bare-metal stents, \% & $0-0.5$ & I.4-I.6 & $0-2.9$ \\
Drug-eluting stents, \% & $0.3-0.4$ & $1.2-1.9$ & $0-3.1$ \\
\hline
\end{tabular}

Note: Reproduced with permission from Lippincott Williams and Wilkins/Wolters Kluwer Health: Cook S, Windecker S. Early stent thrombosis: past, present, and future. Circulation. 2009; I 9:657-659.?

Abbreviations: STEMI, ST segment elevation myocardial infarction; NSTEMI, nonST segment elevation myocardial infarction; $\mathrm{UA}$, unstable angina.

randomized controlled trials of DES, ${ }^{8}$ the incidence was $0.1 \%$ versus $1.0 \%$ in the sirolimus-eluting stent (SES) group and $0.4 \%$ versus $0.3 \%$ in the paclitaxel-eluting stent (PES) group, respectively, as compared with the corresponding BMS group. Most alarmingly however, remains the fact that acute stent thrombosis has been associated with mortality rates of $20 \%-45 \%{ }^{9}$ and myocardial infarction rates of $50 \%-70 \%$. Furthermore, approximately $20 \%$ of patients who have stent thrombosis will have a recurrent episode within 2 years. ${ }^{10}$

\section{Pathophysiology of stent thrombosis}

As with any form of vascular injury, the endothelium plays a pivotal role in the pathogenesis of stent thrombosis. Exposure of the vessel wall to an offending agent results in a stereotypical response of neointimal formation resulting in intimal thickening. ${ }^{11}$ This occurs primarily by smooth muscle proliferation and a multitude of histochemical reactions. Jeong et al studied the effects of crush injury with and without coronary stenting in porcine models. The thrombi formed in both groups were highly platelet-rich; however, stent placement at injury sites enhanced platelet deposition over crush injury alone. ${ }^{12}$

Whether animal models of intervention-related arterial thromboses can be extrapolated to humans has been a matter of some debate. Grewe et $\mathrm{al}^{13}$ analyzed stented vessel segments in 21 autopsy cases with coronary stents implanted from 25 hours to 340 days before death. They noted that in the initial phase, stents were covered by a thin multilayered thrombus, where smooth muscle cells were found as the main cellular component of the neointimal tissue. In 6 weeks, smooth muscle cells formed on the vessel surface, and complete re-endothelialization was first noted 12 weeks after stenting. More recently, Finn et a ${ }^{14}$ performed an autopsy registry study, aiming to identify predictors of LST after DES placement. They showed that the external elastic lamina, plaque area, and stent area were significantly greater in lesions with mural thrombus; however, neointimal growth was less when compared with patent DES lesions.
VLST, defined as stent thrombosis occurring one year after stent implantation, is a distinct entity associated with DES. VLST is proposed to have a multifactorial etiology and in a majority of cases is likely associated with an abnormal vascular response, such as hypersensitivity reaction, excessive fibrin deposit, or neoatherosclerosis. ${ }^{15}$ Nishihira et al reported the development of organized thrombus in patients with VLST. The similar composition of late DES thrombi and de novo coronary thrombi suggests similar mechanisms of symptomatic thrombus formation in patients with DES implantation and de novo acute myocardial infarction. ${ }^{16}$

VLST is also associated with histopathological signs of inflammation and evidence of vessel remodeling on intravascular ultrasound. Cook et a $\mathrm{a}^{17}$ performed an intravascular ultrasound-histopathological correlation, noting that the amount of eosinophils were three times higher in thrombus aspirates from patients with VLST compared with those having other causes of myocardial infarction.

Neoatherosclerosis, or atherosclerosis within the neointima, has been described as peristrut foamy macrophage clusters with or without calcification, thin-cap fibroatheromas, and plaque ruptures without communication with the underlying native atherosclerotic plaque. ${ }^{15}$ Nakazawa et al reviewed registry data from 299 post-PCI autopsies and found that the incidence of neoatherosclerosis was significantly $(P<0.001)$ greater in DES lesions $(31 \%)$ than in BMS lesions $(16 \%) .{ }^{18}$ Furthermore, there are data to support the assertion that neoatherosclerosis with neointimal rupture is another important cause of delayed DES thrombosis. ${ }^{19}$

\section{Factors implicated in stent thrombosis Stent characteristics}

One of the most commonly incriminated factors predisposing to stent thrombosis is the type of coronary stent implanted. The standard teaching that DES are more prone to stent thrombosis while BMS have higher in-stent restenosis rates, although largely true, is overly simplistic when recognizing that there is a great degree of crossover in the pathological mechanisms responsible for both entities. Delayed arterial healing following DES implantation ${ }^{20}$ is characterized by a lack of complete re-endothelialization and persistence of fibrin when compared with BMS. This delayed healing is the primary substrate underlying all cases of late DES thrombosis at autopsy. ${ }^{21}$

DES are impregnated with cytotoxic drugs which act locally to inhibit neointimal hyperplasia and subsequently reduce in-stent restenosis. The stents are coated with 
polymers that are either biodegradable or durable, to slow down release of the active drug. Polymer-free stents coated with sirolimus resulted in less robust neointimal suppression but markedly improved arterial healing compared with the Cypher ${ }^{\circledR}$ DES in the rabbit model..$^{22}$

Overall, the rates of stent thrombosis are highest in first-generation DES, ${ }^{23}$ such as the SES $\left(\right.$ Cypher $\left.^{\circledR}\right)$ and PES $\left(\right.$ Taxus $\left.^{\circledR}\right)$. Stent thrombosis with BMS usually occurs within the first 30 days of implantation, when these stents are prone to thrombus formation. Conversely, with first-generation DES, the greatest concerns are LST and VLST.

Second-generation DES, such as the zotarolimus-eluting stent $\left(\right.$ Endeavor $\left.^{\circledR}\right)$ and everolimus-eluting stents $\left(\right.$ Xience $\left.^{\circledR}\right)$, have demonstrated a decreased risk of LST and VLST. In recent work published by Tada et al from unselected patients in a large German cohort, ${ }^{23}$ the cumulative incidence of definite stent thrombosis at 3 years was $1.5 \%$ with the BMS, 2.2\% with the first-generation DES, and $1.0 \%$ with the second-generation DES. On multivariate analysis, the first-generation DES showed a significantly higher risk of stent thrombosis than the BMS, while second-generation DES were associated with a similar risk of stent thrombosis when compared with the BMS.

Stone et $\mathrm{al}^{24}$ performed a pooled analysis of data from nine double-blind trials in which patients were randomly assigned to receive a BMS or a first-generation DES. Although the 4-year rates of stent thrombosis were higher in the DES groups as compared with the BMS groups, the results were not statistically significant. However, after one year, these higher rates of stent thrombosis in the first-generation DES groups did achieve statistical significance, once again alluding to the fact that the post implantation timing of stent thrombosis is critical to understanding the role of devicerelated risk factors for this entity.

One of the factors that appears to be concerning with respect to the higher rates of stent thrombosis seen in DES is a localized hypersensitivity reaction to the polymer coatings. In porcine models, a high prevalence of diffuse granulomatous inflammation was noted with the SES as compared with the BMS, persisting at 180 days and associated with extensive remodeling of the artery. The PES displayed persistent parastrut fibrin deposition within the neointima and medial smooth muscle cell death at a higher rate than was noted with the SES. ${ }^{25}$

Stent geometry, material, and coatings can affect thrombogenicity. Kolandaivelu et al used ex vivo studies to demonstrate that thick-strutted $(162 \mu \mathrm{m})$ stents were 1.5 -fold more thrombogenic than otherwise identical thin-strutted $(81 \mu \mathrm{m})$ devices $(P<0.001)$, commensurate with a 1.6-fold greater thrombus coverage 3 days after implantation in porcine coronary arteries $(P=0.004) .{ }^{26}$ Tada et al ${ }^{27}$ used optical coherence tomography in patients to determine that thinstrut DES were associated with improved rates of stent strut coverage as compared with thick-strut DES at 6-8 months follow-up. Table 4 shows certain material characteristics of DES and their propensity toward stent thrombosis when compared with BMS.

Biodegradable polymer-coated stents have been proposed as a promising strategy to enhance biocompatibility and improve the delayed healing in the vessel. ${ }^{28}$ These stents use bioabsorbable polymers that dissolve within a specified time period, with the residual metal scaffolding seemingly gaining a safety profile similar to a BMS thereafter. A meta-analysis by Bangalore et al found that biodegradable polymer DES were superior to the PES but inferior to cobalt chromium everolimus-eluting stents with regard to long-term safety, defined in terms of definite stent thrombosis. ${ }^{29}$ Yin et al reported that biodegradable polymer DES were as safe as standard BMS with regard to death, stent thrombosis, and myocardial infarction. ${ }^{28}$

Finally, in an attempt to minimize the long-term risks associated with coronary stent implantation including LST, a bioabsorbable everolimus-eluting scaffold known as the Absorb stent has been studied through several years of follow-up. Serruys et al ${ }^{31}$ used multiple imaging modalities to report that, 2 years after implantation, the stent was bioabsorbed, with vasomotion restored to the arterial segment. Further, the Absorb stent was clinically safe, suggesting freedom from late thrombosis, a finding that remained consistent in the 4-year follow-up results of the ABSORB trial. ${ }^{32}$

Table 4 Select material characteristics of drug-eluting stents

\begin{tabular}{|c|c|c|c|c|}
\hline Stent type & $\begin{array}{l}\text { Paclitaxel-eluting } \\
\text { stent }\end{array}$ & $\begin{array}{l}\text { Sirolimus-eluting } \\
\text { stent }\end{array}$ & $\begin{array}{l}\text { Everolimus-eluting } \\
\text { stent }\end{array}$ & $\begin{array}{l}\text { Zotarolimus-eluting } \\
\text { stent }\end{array}$ \\
\hline Strut $^{30}$ thickness, $\mu \mathrm{m}$ & $97-132$ & 140 & 81 & 91 \\
\hline Platform ${ }^{30}$ material & Stainless steel & Stainless steel & $\begin{array}{l}\text { Cobalt or platinum- } \\
\text { chromium }\end{array}$ & Cobalt-chromium \\
\hline Propensity for ST versus BMS & Greater & Greater & Lower or similar & Lower or similar \\
\hline
\end{tabular}

Abbreviations: ST, stent thrombosis; BMS, bare metal stent. 


\section{Selection of antiplatelet agents and optimal duration of dual antiplatelet therapy}

Post-PCI drug therapy is a delicate balance of preventing thrombotic events while minimizing the hemorrhagic risk that these drugs pose. Some of the earliest data came from Leon et al in $1998,{ }^{33}$ who randomized patients into three treatment groups after successful stent implantation. The chief finding was that a combination of aspirin and ticlopidine was superior to either a combination of warfarin and aspirin or aspirin alone in the prevention of stent thrombosis in these patients.

In 2001, Mehta et al published the results of the PCI-CURE trial, ${ }^{34}$ which demonstrated that long-term administration of clopidogrel in addition to aspirin after PCI was associated with a lower rate of cardiovascular death, myocardial infarction, or any revascularization, with an overall reduction in cardiovascular death or myocardial infarction of $31 \%$. Notably, at follow-up, they showed no significant difference in major bleeding between the groups.

The landmark clinical trial that propelled prasugrel, a novel thienopyridine, to the forefront of interventional cardiology was TRITON-TIMI $38,{ }^{35}$ in which 13,608 patients undergoing PCI were given either prasugrel or clopidogrel (including loading doses). The prasugrel group had lower rates of myocardial infarction, urgent target vessel revascularization, and stent thrombosis $(2.4 \%$ versus $1.1 \% ; P<0.001)$. However, major bleeding, including life-threatening bleeding, was observed in $2.4 \%$ of patients receiving prasugrel and in $1.8 \%$ of patients receiving clopidogrel. Subsequently in 2009, the results of the multicenter randomized PLATO trial were published, exploring the use of ticagrelor, an oral, reversible, direct-acting inhibitor of the adenosine diphosphate receptor, P2Y12. ${ }^{36} \mathrm{In}$ total, 18,624 patients with acute coronary syndrome were given loading and maintenance doses of either ticagrelor or clopidogrel. After one year, the primary end point, a composite of death from vascular causes, myocardial infarction, or stroke, had occurred in $9.8 \%$ of patients receiving ticagrelor as compared with $11.7 \%$ of those receiving clopidogrel, a finding of statistical significance. While no significant difference in overall rates of major bleeding were noted, ticagrelor was associated with a higher rate of major bleeding not related to coronary artery bypass grafting, including more instances of fatal intracranial bleeding. Further, dyspnea was reported in $13.8 \%$ of the ticagrelor group versus $7.8 \%$ of the clopidogrel group, a significant finding that has become well known in the adverse effect profile of ticagrelor today. Among patients who received a stent during the study, the rate of definite stent thrombosis was lower in the ticagrelor group than in the clopidogrel group ( $1.3 \%$ versus $1.9 \% ; P=0.009)$, thus clearly showing a benefit of using ticagrelor in appropriately selected patients with acute coronary syndromes.

Resistance to antiplatelet agents has always been a very serious issue, but gained prominence with the initiation of DES use. In a prospective study by Matetzky et al, ${ }^{37} 60$ patients with ST segment myocardial infarction (STEMI) post PCI were given clopidogrel and the percentage reduction of adenosine diphosphate-induced platelet aggregation was used to divide them into four subgroups. Forty percent of patients in the group with the highest clopidogrel resistance had a recurrent cardiovascular event during 6 months of follow-up. In registry data, patients with acute myocardial infarction who were receiving clopidogrel and carrying cytochrome P450 2C19 loss-of-function alleles had a higher rate of subsequent cardiovascular events, including stent thrombosis. ${ }^{38,39}$ This effect was particularly marked among patients undergoing PCI.

In addition to assessing the best antiplatelet regimen, a great deal of effort has been spent on ascertaining the optimal duration of dual antiplatelet therapy after PCI. Steinhubl et $\mathrm{a}^{40}$ showed that long-term (one-year) clopidogrel therapy significantly reduced the risk of adverse ischemic events in patients who underwent PCI, albeit with a nonsignificant trend of increased bleeding.

A prospective observational cohort study by Iakovou et $\mathrm{al}^{41}$ looked at rates of stent thrombosis after first-generation DES implantation. Aspirin was continued indefinitely and clopidogrel or ticlopidine for at least 3 months after implantation of a SES and for at least 6 months after implantation of a PES. In the patients who discontinued antiplatelet therapy prematurely, a statistically significant $29 \%$ developed stent thrombosis. Another DES cohort study by Daemen et al showed that dual antiplatelet therapy was being taken by $87 \%$ of patients with early stent thrombosis and $23 \%$ of patients with LST. ${ }^{42}$ Kuchulakanti et al showed that the incidence of discontinuation of clopidogrel therapy was significantly higher in patients with stent thrombosis compared with those without stent thrombosis $(36.8 \%$ versus $10.7 \% ; P<0.001){ }^{43}$

Amidst the long-standing debate regarding the benefit of longer versus shorter dual antiplatelet regimens, came the recently published results of the Dual Antiplatelet Therapy (DAPT) study ${ }^{44}$ a multicenter, randomized, placebocontrolled trial. The trial assessed 9961 patients who had undergone DES placement and were on aspirin. These patients were treated with 12 months of a thienopyridine drug (clopidogrel or prasugrel), and were then randomly assigned to continue receiving the thienopyridine or to receive a placebo for another 18 months. 
Continued treatment with thienopyridines, as compared with placebo, reduced the rates of ST $(0.4 \%$ vs $1.4 \%$; $P<0.001)$, and major adverse cardiovascular and cerebrovascular events ( $4.3 \%$ vs. $5.9 \% ; P<0.001)$. However, the rate of moderate or severe bleeding was increased with continued thienopyridine treatment $(2.5 \%$ vs $1.6 \%, P=0.001)$. An interesting observation made by the investigators for both groups, was that an elevated risk of ST and MI existed during the first 3 months after discontinuing the thienopyridine treatment.

\section{Angioplasty-related factors}

There are expansive data on the procedural factors that increase the risk for stent thrombosis. These studies have been performed in multiple different ways, including the use of intravascular ultrasound and optical coherence tomography as well as use of autopsies and histopathologic data. A number of clear and specific angiographic findings have been associated with higher rates of stent thrombosis. Probably the best known of these is incomplete stent strut coverage, which has been found to be a direct correlate of poor endothelialization of the implanted stent. ${ }^{14}$ Figure 1 is a representation of incomplete stent strut coverage as a result of inadequate endothelial coverage.

Deployment-associated factors, like underexpansion and malaposition ${ }^{17}$ of the stent have also been implicated, especially since they can be easily discovered with sophisticated intracoronary imaging techniques. Fujii et $\mathrm{al}^{45}$ used intravascular ultrasound to report that minimum stent cross-sectional area and stent expansion were significantly smaller in their stent thrombosis group than in matched control patients, in their study using SES. A small observational study by Alfonso et al, ${ }^{46}$ also using intravascular ultrasound, showed evidence of severe stent underexpansion in most patients, and no patient in that study fulfilled the standard criteria for optimal stent implantation.
Although performed several years ago, a meta-analysis by Cutlip et $\mathrm{al}^{47}$ showed that the most significant predictors of stent thrombosis included persistent dissection after stenting, longer stent length, and final minimal luminal diameter within the stent. In an attempt to study the etiology of VLST, Cook et al ${ }^{48}$ also showed that, compared with DES controls, patients with VLST had longer lesions and stents, more stents per lesion, and stent overlap. This was again demonstrated by the Dutch Stent Thrombosis Registry where, in addition to stent length, multiple stents were shown to be associated with higher rates of stent thrombosis. ${ }^{49}$

Finally, there are data to suggest that a distinct intimal histopathologic response occurs after DES placement in acute coronary syndromes that may predispose to stent thrombosis. This is especially apparent in patients with STEMI, ${ }^{50}$ who were shown to have a higher incidence of incomplete stent apposition and uncovered struts after primary PCI. Oyabu et $\mathrm{al}^{51}$ used angioscopy to analyze the underlying vessel characteristics after DES and BMS implantation and noted that the thrombogenic potential in DES-implanted lesions may be sustained by inhibition of neointima formation over thrombogenic plaques. Holmes et $\mathrm{al}^{9}$ reiterated that DES struts embedded in the necrotic lipid core demonstrate incomplete healing and reduced neointimal coverage compared with struts imbedded in adjacent stable fibrocalcific plaque.

In summary, the procedural factors that predispose to ST were largely influenced by the advent of DES and subsequent development of a practice that aimed to treat the entire coronary lesion. This dictum led to the use of longer stents $^{52}$ and resulted in technical difficulties associated with their deployment, such as incomplete stent apposition ${ }^{47}$ and resultant shear stress. ${ }^{45}$
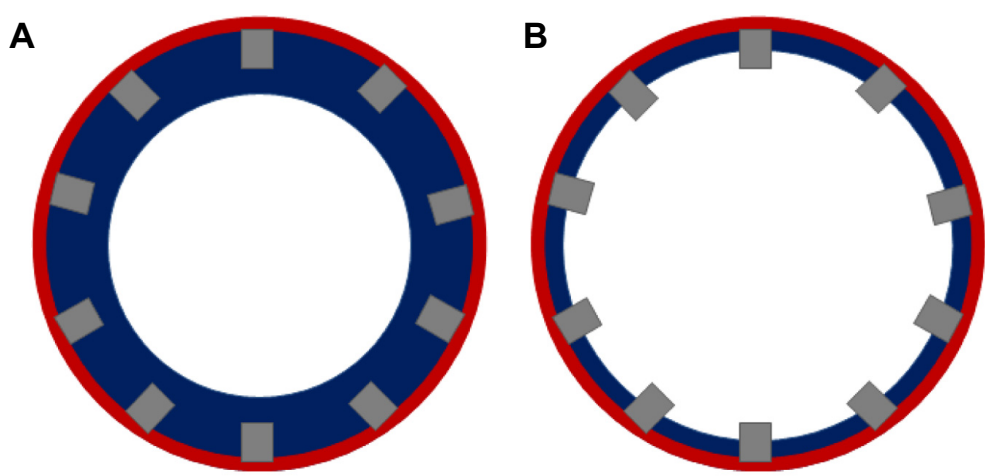

Figure I Incomplete stent strut coverage.

Notes: (A) A well-expanded stent with adequate stent strut coverage by endothelialization. (B) Poor neointimal coverage of similar stent struts, creating a risk factor for stent thrombosis. Red indicates arterial wall; blue indicates neointimal coverage; gray indicates stent strut. 


\section{Lesion-related factors}

It remains fairly consistent across much of the published literature, that over and above the lesion characteristics themselves, it is the extent and acuity of pre-existing coronary disease that directly correlates with the risk of stent thrombosis. Patients with acute coronary syndrome are at higher risk of early stent thrombosis and LST with either BMS or DES..$^{53}$ A potential reason for this has been ascribed to the presence of ruptured plaques and necrotic lipid cores, which are seen particularly in patients with STEMI. ${ }^{15,54}$

There are also certain specific lesion characteristics, possibly as well as the location of the lesion itself, which are associated with a predilection for stent thrombosis. Known factors associated with stent thrombosis are lesion length, location, and diameter. Complex lesions, including chronic total occlusions and bifurcation lesions, as well as lesions that occur in vein grafts from previous bypass surgeries, are associated with an increased risk of stent thrombosis..$^{55}$

Cohort studies and large volume registry data have shown that patients with angiographically confirmed stent thrombosis have a higher incidence of lesions in the left anterior descending artery. ${ }^{43,50,56}$ Registry data obtained from 20 centers in Spain also demonstrated that the occurrence of stent thrombosis in longer lesions was statistically significant. ${ }^{56}$ Iakovu et al showed that for subacute thrombosis, stent length was a predictor; for each $1 \mathrm{~mm}$ increase in length, there was a 1.03 times greater risk of thrombosis. ${ }^{41}$ Ong et $\mathrm{al}^{57}$ showed that bifurcation stenting in the setting of acute myocardial infarction was an independent risk factor for angiographic stent thrombosis in their entire study population.

\section{Medical comorbidities}

While much has been said about devices and medications, the underlying medical conditions that patients suffer with can play a huge role in the occurrence of stent thrombosis. The heralding presentation of the events that warrant PCI clearly influences the rates of stent thrombosis, with STEMI patients posing a higher risk than patients with stable coronary artery disease. ${ }^{54,56}$

There are also various underlying disease processes associated with an increased incidence of stent thrombosis that have emerged from subgroup analysis data. End-stage renal disease $^{41,43}$ and diabetes mellitus ${ }^{5,42}$ have been identified as major culprits for the occurrence of stent thrombosis. Diabetics were found to have double the rates of stent thrombosis when compared with nondiabetics, with insulin dependence being an associated risk factor. ${ }^{58}$
Registry data has been very useful in delineating the medical conditions that are related to stent thrombosis. The Dutch Stent Thrombosis Registry ${ }^{49}$ cited present malignancy, ejection fraction $<30 \%$, and younger age as risks for stent thrombosis. Similarly, the RESTART trial from Japan ${ }^{59}$ differentiated the predictors for VLST from those for LST, including hemodialysis, heart failure, insulin-dependent diabetes mellitus, and low body mass index in the former category. A very large multicenter registry from Spain ${ }^{56}$ reported that independent predictors for subacute stent thrombosis, analyzed in a subgroup of 14,120 cases, were diabetes, renal failure, acute coronary syndrome, and STEMI. Older age and ejection fraction $<45 \%$ were independent predictors for mortality as well.

Finally, some fairly robust data comes from the HORIZONS-AMI trial, ${ }^{60}$ which enrolled 3,602 STEMI patients undergoing primary PCI. Patients with stent thrombosis at any time point within the 2-year follow-up period were analyzed and compared with patients without stent thrombosis. Patients with stent thrombosis were noted to be younger and to have higher rates of insulin-treated diabetes mellitus, current smoking, prior myocardial infarction, prior PCI, and a higher baseline platelet count.

\section{Patient-related factors}

While much has been written about the role of dual antiplatelet therapy in the prevention of stent thrombosis, there are certain ancillary issues associated with the use of these medications that are not routinely addressed in the literature. Probably the most important of these is the role of patient compliance. Given that most patients are on a regimen of multiple medications, it is crucial that they recognize the importance of continuing dual antiplatelet therapy for the prescribed period of time. In-hospital teaching, with emphasis on the life-threatening consequences of prematurely stopping these drugs is imperative prior to discharge, as is a clear understanding of dosing regimens.

Similarly, the ease of procuring medications is paramount. Lack of adequate refills, access to pharmacies, and availability of physicians to replenish supplies are some of the triggers for poor compliance in post-PCI patients. This has assumed a new level of significance as we see newer antiplatelet agents routinely prescribed. It is ideal to ensure, prior to discharge, that the patient's pharmacy carries the intended medication and that the patient can afford the cost of therapy or has access to subsidized medications, especially when the duration of dual antiplatelet therapy is a year or longer.

Lastly, with longer dual antiplatelet therapy regimens, awareness about any planned and necessary procedures in 
the near future should be factored into the original choice of stent. Educating and specifically informing the patient and family about the necessity to discuss these types of decisions with their cardiologist can help to circumvent such issues and prevent catastrophic outcomes. Table 5 summarizes the risk factors that have been associated with increased rates of stent thrombosis.

\section{Stent thrombosis: the literature at a glance}

While there are vast expanses of literature devoted to coronary stents and their complications, randomized controlled trials looking primarily at stent thrombosis are fewer in number. Much of the data has been extrapolated from larger clinical trials of DES and supplemented by large observational studies and registry data. Another important distinction in the trials related to stent thrombosis are the patient populations that were included in the studies. While many trials used low-risk patients with stable coronary artery disease, there are significantly fewer trials that looked at patients with acute coronary syndromes, in particular patients with STEMI, who we now know are at higher risk for stent thrombosis. Below we detail the findings from some of the larger clinical trials, categorized by type of trial and patient population. Table 6 summarizes pertinent data from the major registries and randomized controlled trials that have evaluated the use of DES in varying presentations of coronary artery disease.

\section{Randomized controlled trials}

In 2002, Morice et $\mathrm{l}^{61}$ performed a randomized double-blind trial in 238 patients to compare the SES with standard BMS for revascularization of single primary lesions in native coronary arteries. At 6 months, the degree of neointimal proliferation, manifested as mean late luminal loss, was significantly lower in the SES group than in the standard stent group $(P<0.001)$. There were no episodes of stent thrombosis seen during one year of follow-up.

The original SIRIUS trial looked at SES compared with BMS in patients with de novo native coronary artery lesions and initially followed them for one year. ${ }^{62}$ At one year, there was no significant difference in rates of stent thrombosis between the two groups. Further, at 5-year follow-up, no significant differences were observed in the cumulative incidence of stent thrombosis for sirolimus versus control patients with either protocol-derived (1.0\% versus $0.8 \%$, respectively) or ARC definitions (3.9\% versus $4.2 \%){ }^{63}$

Everolimus is a semisynthetic immunosuppressant that is an analog of rapamycin. It acts by blocking the stimulatory effects of growth factors and cytokines released after vascular injury and thereby inhibits smooth muscle cell proliferation. ${ }^{64}$ The FUTURE-I study ${ }^{65}$ was the first human evaluation of the everolimus-eluting stent for the treatment of noncomplex coronary lesions. This study demonstrated significantly lower in-stent late lumen loss and in-segment diameter stenoses when compared with the BMS. The first-in-man randomized controlled trial assessing the safety and efficacy of the everolimus-eluting stent was SPIRIT FIRST, ${ }^{66}$ which also found significant suppression of neointimal growth at 6 months when compared with the BMS. Subsequently, the SPIRIT IV ${ }^{67}$ and COMPARE ${ }^{68}$ trials compared the everolimus-eluting stent with the PES in patients with stable coronary artery disease, and both showed a statistically significant lowering in the rate of stent thrombosis with second-generation DES.

\section{Large-scale registry data}

The Dutch Stent Thrombosis Registry ${ }^{49}$ was aimed at comprehensively identifying predictors of stent thrombosis. Of 21,009 registry patients treated with a BMS or a DES, $2.1 \%$

Table 5 Risk factors associated with higher rates of stent thrombosis

\begin{tabular}{lllll}
\hline Stent characteristics & APT associations & $\begin{array}{l}\text { Angioplasty-related } \\
\text { factors }\end{array}$ & $\begin{array}{l}\text { Lesion-related } \\
\text { factors }\end{array}$ & Medical comorbidities \\
\hline First-generation DES & Discontinuation of APT & Stent underexpansion & Length & Diabetes (insulin-dependent) \\
Inflammation or hypersensitivity & APT resistance & $\begin{array}{l}\text { Incomplete strut coverage } \\
\text { to DES coating }\end{array}$ & Location & $\begin{array}{l}\text { Renal failure } \\
\text { Low ejection fraction }\end{array}$ \\
& & Stent-associated dissection & Complexity & ACS as presentation \\
& Downstream/upstream CAD & Underlying clinical & Predisposing thrombogenic \\
& & presentation (STEMI) & conditions \\
& & Vulnerable neoatheromas & Multivessel CAD & Cigarette smoking \\
\hline
\end{tabular}

Abbreviations: ACS, acute coronary syndrome; APT, antiplatelet therapy; DES, drug-eluting stent; CAD, coronary artery disease; STEMI, ST segment elevation myocardial infarction. 
Table 6 Major clinical trials from which data for stent thrombosis have been derived

\begin{tabular}{|c|c|c|c|c|}
\hline $\mathrm{RCT} /$ registry & Stent comparison & Patients (n) & Acuity of CAD & Results related to ST (\%) \\
\hline SIRIUS 62 & SES vs BMS & 1,058 & De novo CAD & 0.4 vs $0.8(P=0.448)$ \\
\hline C-SIRIUS 69 & SES vs BMS & 100 & De novo CAD (small vessel) & 0.01 vs $0.01 \quad(P=1.0)$ \\
\hline TAXUS-170 & PES vs BMS & 61 & De novo CAD or restenotic lesion & 0 vs 0 \\
\hline \multirow[t]{2}{*}{ TAXUS-II } & PES-SR vs & 536 & De novo CAD & 2.7 vs 1.7 vs $0.8(P=0.32)$ \\
\hline & PES-MR vs BMS & & & \\
\hline TAXUS-IV72 & PES vs BMS & & De novo CAD (single vessel) & 0.8 vs $0.8(P=0.98)$ \\
\hline TAXUS-V ISR ${ }^{73}$ & Brachytherapy vs PES & 396 & ISR in prior BMS & 2.6 vs $1.6(P=0.72)$ \\
\hline \multirow[t]{2}{*}{ OPTIMIST $^{74, *}$} & (Extrapolated) & 100 & Angiographically proven ST & 50 vs 39 vs II \\
\hline & DES vs BMS vs unascertained stent & & & \\
\hline SPIRIT IV ${ }^{67}$ & EES vs PES & 3,687 & De novo CAD & 0.2 vs $0.8(P=0.004)$ \\
\hline COMPARE $^{68}$ & EES vs PES & $\mathrm{I}, 800$ & De novo CAD & 0.7 vs $2.6(P=0.002)$ \\
\hline \multirow[t]{2}{*}{ ACUITY75 } & (Extrapolated) & 3,405 & ACS & I.4 vs I.4 $(P=1.00)$ \\
\hline & DES (89\%) vs BMS (11\%) & & & \\
\hline
\end{tabular}

Note: *OPTIMIST trial primarily looked at optimal angiographic reperfusion rates in patients with angiographically proven ST.

Abbreviations: RCT, randomized controlled trial; CAD, coronary artery disease; ST, stent thrombosis; BMS, bare metal stent; SES, sirolimus-eluting stent; ISR, in-stent restenosis; DES, drug-eluting stent; PES, paclitaxel-eluting stent; SR, slow release; MR, moderate release; EES, everolimus-eluting stent; ACS, acute coronary syndrome; vs, versus.

presented with definite stent thrombosis. A total of 140 stent thromboses were acute, 180 were subacute, 58 were late, and 59 were very late.

Another large-scale, multicenter Spanish registry ${ }^{56}$ enrolled 23,500 patients treated with DES, in whom definite stent thrombosis developed in 301 patients, with 24 being acute, 125 being subacute, and 152 being late. The cumulative incidence of stent thrombosis after DES implantation was $2 \%$ at 3 years, but no differences were found between types of stent.

\section{Clinical trials looking at patients with STEMI/acute coronary syndrome}

Stone et $\mathrm{al}^{76}$ randomly assigned 3,006 patients (in a 3:1 ratio) with STEMI to receive a PES or a BMS. The two primary end points of the study were the 12-month rates of target vessel revascularization for ischemia and a composite safety outcome measure of death, reinfarction, stroke, or stent thrombosis (powered for noninferiority). Patients who received the PES had significantly lower 12-month rates of ischemia-driven target vessel revascularization and noninferior rates for the composite safety end points. However, both groups had similar 12-month rates of death $(3.5 \%$ and $3.5 \%$, respectively; $P=0.98)$ and stent thrombosis $(3.2 \%$ and $3.4 \%$, respectively; $P=0.77$ ).

Mauri et $\mathrm{al}^{77}$ conducted an observational study in an unselected cohort of 7,217 patients with acute myocardial infarction undergoing PCI. Propensity score matching was used to balance the two groups of patients who received a DES versus a BMS. While there was a significant decrease in mortality in the group receiving DES, the difference in 2-year reinfarction rates was not statistically significant between the two groups other than in patients with non-STEMI. Although stent thrombosis was not specifically looked at as an outcome in this study, the lack of significant reinfarction at follow-up in the STEMI groups provides some useful data.

The prospective randomized ACUITY trial ${ }^{75}$ performed coronary angiographic analyses on 3,405 patients with moderate-risk and high-risk acute coronary syndrome in whom stents were implanted. Within 30 days, definite or probable stent thrombosis occurred in 48 patients (1.4\%). Stent thrombosis rates were not significantly different in patients treated with BMS compared with DES (1.4\% versus $1.4 \% ; P=1.00)$.

Very recently, Sarno et al published results concerning 34,147 patients enrolled in the SCAAR study. ${ }^{78}$ Each of these patients presented with STEMI and was treated by PCI with either a new-generation DES (Endeavor Resolute, Xience V or Xience Prime, Promus or Promus Element), an older-generation DES (Cypher, Cypher Select, Taxus Express, Taxus Liberté, and Endeavor), or a BMS. The study reported a significantly lower risk of stent thrombosis during the first year after PCI with both the new-generation and older-generation DES as compared with the BMS, but a higher risk of VLST, occurring up to 3 years later in the older-generation DES group as compared with the BMS group. There was a similar risk of VLST in the new-generation DES and BMS groups. The investigators surmised that STEMI patients could have an increased risk of stent thrombosis due to increased platelet activity and delayed healing at the culprit site. ${ }^{78}$

\section{Intraprocedural stent thrombosis}

Thrombus formation during stent implantation, defined as intraprocedural stent thrombosis (IPST), was a rare event in 
the BMS era. ${ }^{79}$ Some of the earliest published data looking at IPST during first-generation DES implantation comes from Chieffo et al, ${ }^{79}$ who studied 670 patients with 1,362 lesions treated with the Cypher DES. Five of these patients had IPST, defined as an angiographically confirmed intraluminal filling defect within the stent resulting in TIMI grade 0 or 1 anterograde flow. Notably, all of these patients had been pretreated with thienopyridines. However, none of them received elective glycoprotein IIb/IIIa inhibitors, a practice that was relatively routine at that time. Further, of all the variables studied, only the total stent length per vessel had a statistically significant association with the occurrence of IPST. Similar findings were published after analysis of the RECIPE study by BiondiZoccai et al, seeking to validate the predictors of IPST after DES implantation. ${ }^{80}$ Their research showed that IPST occurred in $0.5 \%$ of their 1,320 study subjects and was predicted by number and total length of implanted stents, baseline minimal lumen diameter, and use of glycoprotein IIb/IIIa inhibitors.

$\mathrm{Xu}$ et al performed a retrospective study of 1,901 patients with acute coronary syndrome who underwent primary PCI. ${ }^{81}$ Patients with IPST demonstrated involvement of significantly more bifurcation lesions and had more thrombus burden at baseline. The IPST group also had more major adverse cardiac events at their 30-day and one-year follow-ups. A very similarly designed but much larger study conducted by Brener et al examined angiograms from 6,591 patients enrolled in two large-scale clinical trials, and $0.7 \%$ of them were noted to have IPST. ${ }^{82}$ The occurrence of IPST in their data was associated with STEMI at presentation, a high white blood cell count, treatment of thrombotic and bifurcation lesions, bivalirudin monotherapy, bail-out use of IIb/IIIa inhibitors, and BMS implantation. The number of major adverse ischemic events was markedly higher in patients with IPST versus those without IPST, including mortality at 30 days and one year.

Généreux et al performed a frame-by-frame angiographic analysis in 10,939 patients enrolled in the CHAMPION PHOENIX trial that sought to compare clopidogrel with cangrelor, a potent, reversible, intravenous, direct-acting platelet adenosine diphosphate $\mathrm{P} 2 \mathrm{Y}_{12}$ inhibitor. ${ }^{83}$ IPST developed in $0.8 \%$ of the total sample size, although the rate was significantly lower in the group treated with cangrelor. IPST was associated with a marked increase in composite ischemia or new-onset out-of-laboratory stent thrombosis at 48 hours and at 30 days.

\section{Future directions and strategies for prevention}

Stent thrombosis is a condition that has evolved considerably along with the evolution of PCI, with tremendous volumes of published literature available. As newer and more advanced stents have arrived at catheterization laboratories, the incidence and presentation of this entity has transformed dramatically over many years, although much yet remains to be discovered. Amalgamating the evidence garnered from structured clinical trials, real-world data, and anecdotal evidence, the impetus lies in moving forward to design a structured multilevel solution to this ubiquitous problem.

Just as the etiological factors predisposing to stent thrombosis have been categorized under many subheadings, it may be prudent to do the same when evaluating potentially preventive strategies as well. There is accelerated industrydriven momentum to invent newer and better stents, with respect to both design and drug elution. To this end, the 4-year follow-up results of the ABSORB trial ${ }^{32}$ looking at ischemiadriven major adverse cardiac events after implantation of a bioresorbable everolimus-eluting scaffold in patients with de novo coronary artery disease were promising, with no stent thrombosis reported in these patients.

Simultaneously, pharmaceutical companies are striving to refine and redevelop novel antiplatelet agents to improve upon the adverse effect profiles of currently prescribed medications. Given that some duration of dual antiplatelet therapy is essential after any stent implantation, the search is underway for a safe yet potent antiplatelet agent with a lower bleeding risk or some degree of clinically relevant reversibility. While ticagrelor has been found to be partly reversible in vitro by administration of uninhibited platelets, ${ }^{84}$ the clinical applicability of this finding in patients with major bleeding remains uncertain.

Two novel and reversible antiplatelet agents, cangrelor and elinogrel, are available in intravenous form (elinogrel is also available in an oral form). Recent trials have tested these agents against clopidogrel regarding efficacy and safety outcomes. While resulting in fewer bleeding events during heart surgery, these reversible antiplatelet agents, like ticagrelor, carry the risk of potential autoimmune reactions manifesting as dyspnea, which is a potential barrier to their widespread clinical use. ${ }^{85,86}$ Animal studies have also yielded promising results, with preliminary data showing that P2Y1 receptor antagonists (as well as SAR216471, a new P2Y12 inhibitor) have antithrombotic effects with a relatively low bleeding risk. ${ }^{87,88}$

As each new generation of stents is studied, a better understanding of lesion-associated factors and procedural pitfalls will also enable interventional cardiologists and fellows to refine their techniques, with the aid of imaging such as intravascular ultrasound and optical coherence tomography 


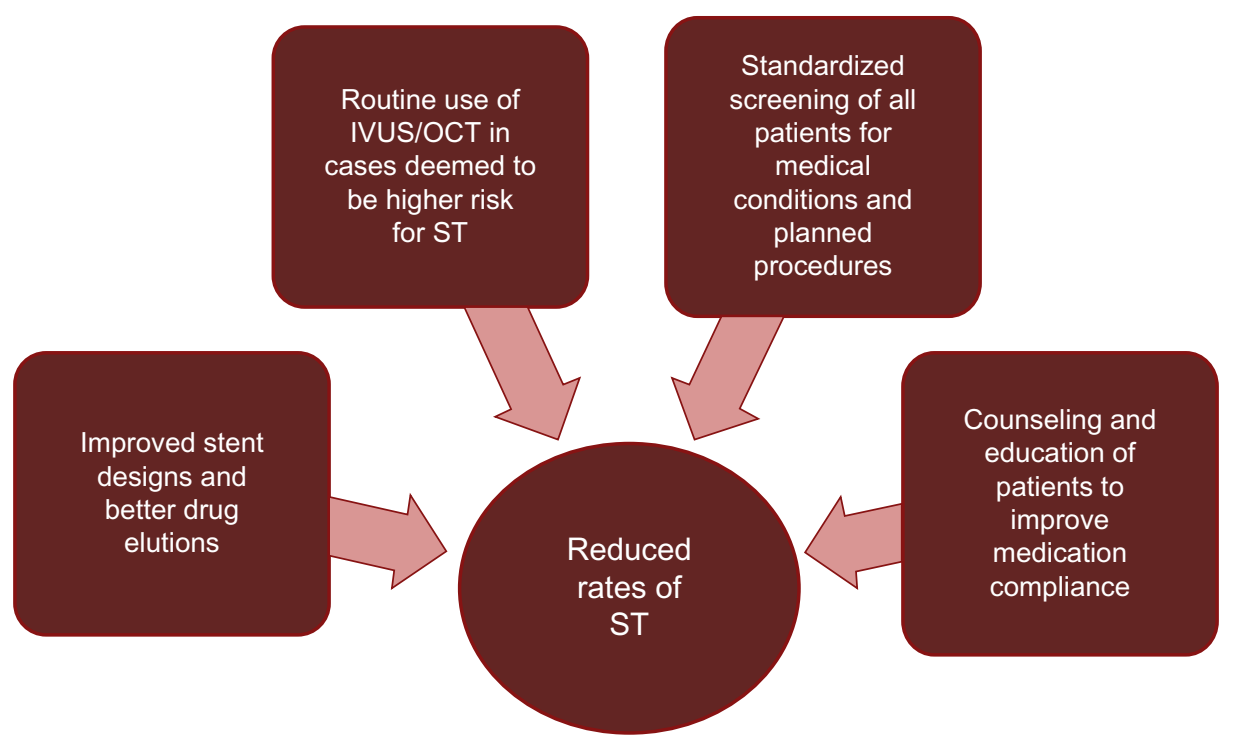

Figure 2 Strategies to prevent stent thrombosis.

Abbreviations: IVUS, intravenous ultrasound; OCT, optical coherence tomography; ST, stent thrombosis.

in cases deemed to be at higher risk for stent thrombosis. Development of standardized guidelines regarding which subsets of patients and lesions should be routinely imaged, may decrease some of the arbitrariness with which post-PCI imaging is used and ensure the best possible outcome in all cases.

However, it is clearly evident that above and beyond any kind of device or procedural risk factor for stent thrombosis, the most unpredictable variable is the patient. Baseline medical conditions, planned surgeries, bleeding issues, resistance to antiplatelet agents, and social factors that influence compliance with medication are only some of the stumbling blocks that facilitate occurrence of stent thrombosis. Ensuring appropriate screening of patients prior to PCI, admittedly challenging in the STEMI population, which poses one of the highest thrombotic risks, may mitigate these issues to some extent. Figure 2 highlights various strategies that may be used to diminish the risk of stent thrombosis.

Dangas et al looked at the validity of a risk score to predict stent thrombosis using data from two large randomized controlled trials with a total of 6,139 patients undergoing PCI for acute coronary syndrome ${ }^{89}$ The study population was divided into two cohorts, one for risk score development and the other for validation. The score incorporated clinical, angiographic, and procedural variables, and studied rates of stent thrombosis in low-risk, intermediate-risk, and high-risk categories. While the scoring system may still prove to be a useful risk stratification tool, a subsequent editorial comment by Waksman and Barbash ${ }^{90}$ highlighted that the study primarily looked at first-generation DES and did not study the effects of well-known predictors of stent thrombosis, such as early cessation of antiplatelet therapy or factors related to stent deployment, thus questioning the applicability of such a risk score in routine clinical practice.

\section{Conclusion}

Stent thrombosis is a truly perplexing clinical entity and lowering its incidence is crucial, both for clinical safety as well as peace of mind for patients and physicians alike. Given that STEMI patients are one of the highest risk groups for developing stent thrombosis after primary PCI, this may be an ideal arena to focus research efforts, particularly randomized controlled trials, going forward. Appropriate patient selection, based on rigorous screening protocols when circumstances permit, will help physicians choose the appropriate stent in each case and minimize complications related to underlying medical conditions, socioeconomic factors, and pharmaceutical nonadherence. Overall in a clinical context however, using the current data to derive a diverse and multifaceted approach to coronary revascularization, focusing on both patient-related and procedure-related factors, will likely yield the highest long-term benefits in the challenging world of stent thrombosis.

\section{Disclosure}

The authors report no conflicts of interest in this work.

\section{References}

1. Sigwart U, Puel J, Mirkovitch V, Joffre F, Kappenberger L. Intravascular stents to prevent occlusion and restenosis after transluminal angioplasty. N Engl J Med. 1987;316:701-706. 
2. Cutlip DE, Windecker S, Mehran R, et al. Academic Research Consortium. Academic Research Consortium clinical end points in coronary stent trials: a case for standardized definitions. Circulation. 2007; 115:2344-2351.

3. Cutlip DE, Nakazawa G, Krucoff MW, et al. Autopsy validation study of the Academic Research Consortium stent thrombosis definition. JACC Cardiovasc Interv. 2011;4:554-559.

4. Levine GN, Bates ER, Blankenship JC, et al. 2011 ACCF/AHA/ SCAI guideline for percutaneous coronary intervention: a report of the American College of Cardiology Foundation/American Heart Association Task Force on Practice Guidelines and the Society for Cardiovascular Angiography and Interventions. $\mathrm{J} \mathrm{Am} \mathrm{Coll} \mathrm{Cardiol.}$ 2011;58:e44-e122.

5. Wenaweser P, Daemen J, Zwahlen M, et al. Incidence and correlates of drug-eluting stent thrombosis in routine clinical practice. 4-year results from a large 2-institutional cohort study. $\mathrm{J} \mathrm{Am} \mathrm{Coll} \mathrm{Cardiol.}$ 2008;52:1134-1140.

7. Cook S, Windecker S. Early stent thrombosis: past, present, and future. Circulation. 2009;119:657-659.

6. Doyle B, Rihal CS, O'Sullivan CJ. Outcomes of stent thrombosis and restenosis during extended follow-up of patients treated with bare-metal coronary stents. Circulation. 2007;116:2391-2398.

8. Mauri L, Hsieh WH, Massaro JM, Ho KK, D’Agostino R, Cutlip DE. Stent thrombosis in randomized clinical trials of drug-eluting stents. N Engl J Med. 2007;356:1020-1029.

9. Holmes DR Jr, Kereiakes DJ, Garg S, et al. Stent thrombosis. JAm Coll Cardiol. 2010;56:1357-1365.

10. Kirtane AJ, Stone GW. How to minimize stent thrombosis. Circulation. 2011;124:1283-1287.

11. Robbins SL, Kumar V, Cotran RS. Robbins and Cotran Pathologic Basis of Disease. 8th ed. Philadelphia, PA, USA: Saunders/Elsevier; 2010.

12. Jeong MH, Owen WG, Staab ME, et al. Porcine model of stent thrombosis: platelets are the primary component of acute stent closure. Cathet Cardiovasc Diagn. 1996;38:38-43.

13. Grewe P, Deneke T, Machraoui A, Barmeyer J, Müller K. Acute and chronic tissue response to coronary stent implantation: pathologic findings in human specimen. $J$ Am Coll Cardiol. 2000;35: 157-163.

14. Finn AV, Joner M, Nakazawa G, et al. Pathological correlates of late drug-eluting stent thrombosis: strut coverage as a marker of endothelialization. Circulation. 2007;115:2435-2441.

15. Nakazawa G. Stent thrombosis of drug eluting stent: pathological perspective. J Cardiol. 2011;58:84-91.

16. Nishihira K, Yamashita A, Ishikawa T, Hatakeyama K, Shibata Y, Asada Y. Composition of thrombi in late drug-eluting stent thrombosis versus de novo acute myocardial infarction. Thromb Res. 2010;126: 254-257.

17. Cook S, Ladich E, Nakazawa G, et al. Correlation of intravascular ultrasound findings with histopathological analysis of thrombus aspirates in patients with very late drug-eluting stent thrombosis. Circulation. 2009;120:391-399.

18. Nakazawa G, Otsuka F, Nakano M, et al. The pathology of neoatherosclerosis in human coronary implants: bare-metal and drug-eluting stents. J Am Coll Cardiol. 2011;57:1314-1322.

19. Finn AV, Otsuka F. Neoatherosclerosis: a culprit in very late stent thrombosis. Circ Cardiovasc Interv. 2012;5:6-9.

20. Byrne RA, Joner M, Kastrati A. Polymer coatings and delayed arterial healing following drug-eluting stent implantation. Minerva Cardioangiol. 2009;57:567-584.

21. Finn AV, Nakazawa G, Joner M. Vascular responses to drug eluting stents: importance of delayed healing. Arterioscler Thromb Vasc Biol. 2007;27:1500-1510.

22. John MC, Wessely R, Kastrati A. Differential healing responses in polymer- and nonpolymer-based sirolimus-eluting stents. JACC Cardiovasc Interv. 2008;1:535-544.
23. Tada T, Byrne RA, Simunovic I, et al. Risk of stent thrombosis among bare-metal stents, first-generation drug-eluting stents, and secondgeneration drug-eluting stents: results from a registry of 18,334 patients. JACC Cardiovasc Interv. 2013;6:1267-1274.

24. Stone GW, Moses JW, Ellis SG, et al. Safety and efficacy of sirolimusand paclitaxel-eluting coronary stents. N Engl J Med. 2007;356: 998-1008.

25. Wilson GJ, Nkazawa G, Schwartz RS, et al. Comparison of inflammatory response after implantation of sirolimus and paclitaxel-eluting stents in porcine coronary arteries. Circulation. 2009;120:141-149.

26. Kolandaivelu K, Swaminathan R, Gibson WJ, et al. Stent thrombogenicity early in high-risk interventional settings is driven by stent design and deployment and protected by polymer-drug coatings. Circulation. 2011;123:1400-1409.

27. Tada T, Byrne RA, Dimopoulos A, et al. Impact of stent strut thickness on arterial healing after drug-eluting stents implantation assessed by optical coherence tomography. Eur Heart J. 2013;34 Suppl 1:3935.

28. Yin Y, Zhang Y, Zhao X. Safety and efficacy of biodegradable drugeluting vs bare metal stents: a meta-analysis from randomized trials. PLoS One. 2014;9:e99648.

29. Bangalore S, Toklu B, Amoroso N, et al. Bare metal stents, durable polymer drug eluting stents, and biodegradable polymer drug eluting stents for coronary artery disease: mixed treatment comparison metaanalysis. BMJ. 2013;347:f6625.

30. Stefanini GG, Holmes DR Jr. Drug-eluting coronary-artery stents. N Engl J Med. 2013;368:254-265.

31. Serruys PW, Ormiston JA, Onuma Y, et al. A bioabsorbable everolimuseluting coronary stent system (ABSORB): 2-year outcomes and results from multiple imaging methods. Lancet. 2009;373:897-910.

32. Dudek D, Onuma Y, Ormiston JA, Thuesen L, Miquel-Hebert K, Serruys PW. Four-year clinical follow-up of the ABSORB everolimuseluting bioresorbable vascular scaffold in patients with de novo coronary artery disease: the ABSORB trial. EuroIntervention. 2012;7: 1060-1061.

33. Leon MB, Baim DS, Popma JJ, et al. A clinical trial comparing three anti-thrombotic drug regimens after coronary artery stenting. $N$ Engl J Med. 1998;338:1665-1671.

34. Mehta SR, Yusuf S, Peters RJ, et al; Clopidogrel in Unstable angina to prevent Recurrent Events trial (CURE) Investigators. Effects of pretreatment with clopidogrel and aspirin followed by long-term therapy in patients undergoing percutaneous coronary intervention. the PCI-CURE study. Lancet. 2001;358:527-533.

35. Wiviott SD, Braunwald E, McCabe CH, et al; TRITON-TIMI 38 Investigators. Prasugrel versus clopidogrel in patients with acute coronary syndromes. N Engl J Med. 2007;357:2001-2015.

36. Wallentin L, Becker RC, Budaj A, et al; PLATO Investigators. Ticagrelor versus clopidogrel in patients with acute coronary syndromes. $N \mathrm{Engl}$ J Med. 2009;361:1045-1057.

37. Matetzky S, Shenkman B, Guetta V, et al. Clopidogrel resistance is associated with increased risk of recurrent atherothrombotic events in patients with acute myocardial infarction. Circulation. 2004;109: 3171-3175.

38. Simon T, Verstuyft C, Mary-Krause M, et al; French Registry of Acute ST-Elevation and Non-ST-Elevation Myocardial Infarction (FAST-MI) Investigators. Genetic determinants of response to clopidogrel and cardiovascular events. $N$ Engl J Med. 2009;360:363-375.

39. Mega J, Close $\mathrm{S}$, Wiviott $\mathrm{S}$, et al. Cytochrome $\mathrm{p}-450$ polymorphisms and response to clopidogrel. N Engl J Med. 2009;360:354-362.

40. Steinhubl SR, Berger PB, Mann JT 3rd, et al; CREDO Investigators. Clopidogrel for the Reduction of Events During Observation. Early and sustained dual oral antiplatelet therapy following percutaneous coronary intervention: a randomized controlled trial. JAMA. 2002;288:2411-2420.

41. Iakovou I, Schmidt T, Bonizzoni E, et al. Incidence, predictors, and outcome of thrombosis after successful implantation of drug-eluting stents. JAMA. 2005;293:2126-2130. 
42. Daemen J, Wenaweser P, Tsuchida K, et al. Early and late coronary stent thrombosis of sirolimus-eluting and paclitaxel-eluting stents in routine clinical practice: data from a large two-institutional cohort study. Lancet. 2007;369:667-678.

43. Kuchulakanti PK, Chu WW, Torguson R, et al. Correlates and long-term outcomes of angiographically proven stent thrombosis with sirolimusand paclitaxel-eluting stents. Circulation. 2006;113:1108-1113.

44. Mauri L, Kereiakes DJ, Yeh RW, et al; DAPT Study Investigators. Twelve or 30 Months of Dual Antiplatelet Therapy after Drug-Eluting Stents. N Engl J Med. 2014;371:2155-2166.

45. Fujii K, Carlier SG, Mintz GS, et al. Stent underexpansion and residual reference segment stenosis are related to stent thrombosis after sirolimus-eluting stent implantation: an intravascular ultrasound study. $\mathrm{J} \mathrm{Am}$ Coll Cardiol. 2005;45:995-998.

46. Alfonso F, Suarez A, Angiolillo DJ, et al. Findings of intravascularultrasound during acute stent thrombosis. Heart. 2004;90:1455-1459.

47. Cutlip DE, Baim DS, Ho KK, et al. Stent thrombosis in the modern era: a pooled analysis of multicenter coronary stent clinical trials Circulation. 2001;103:1967-1971.

48. Cook S, Wenaweser P, Togni M, et al. Incomplete stent apposition and very late stent thrombosis after drug-eluting stent implantation. Circulation. 2007;115:2426-2434.

49. van Werkum JW, Heestermans AA, Zomer AC, et al. Predictors of coronary stent thrombosis: the Dutch Stent Thrombosis Registry. J Am Coll Cardiol. 2009;53:1399-1409.

50. Gonzalo N, Barlis P, Serruys PW. Incomplete stent apposition and delayed tissue coverage are more frequent in drug-eluting stents implanted during primary percutaneous coronary intervention for ST-segment elevation myocardial infarction than in drug-eluting stents implanted for stable/unstable angina: insights from optical coherence tomography. JACC Cardiovasc Interv. 2009;2: 445-452.

51. Oyabu J, Ueda Y, Ogasawara N, Okada K, Hirayama A, Kodama K. Angioscopic evaluation of neointima coverage: sirolimus drug-eluting stent versus bare metal stent. Am Heart J. 2006;152:1168-1174.

52. Joner M, Finn AV, Farb A, et al. Pathology of drug-eluting stents in humans: delayed healing and late thrombotic risk. J Am Coll Cardiol. 2006;48:193-202.

53. Kukreja N, Onuma Y, Garcia-Garcia HM, Daemen J, van Domburg R, Serruys PW. The risk of stent thrombosis in patients with acute coronary syndromes treated with bare-metal and drug-eluting stents. JACC Cardiovasc Interv. 2009;2:534-541.

54. Cheneau E, Leborgne L, Mintz GS, et al. Predictors of subacute stent thrombosis: results of a systematic intravascular ultrasound study. Circulation. 2003;108:43-47.

55. Motovska Z, Knot J, Widimsky P. Stent thrombosis - risk assessment and prevention. Cardiovasc Ther. 2010;28:e92-e100.

56. de la Torre-Hernández JM, Alfonso F, Hernández F, et al; ESTROFA Study Group. Drug-eluting stent thrombosis: results from the multicenter Spanish registry ESTROFA (Estudio ESpañol sobre TROmbosis de stents FArmacoactivos). J Am Coll Cardiol. 2008;51:986-990.

57. Ong AT, Hoye A, Aoki J, et al. Thirty-day incidence and six-month clinical outcome of thrombotic stent occlusion after bare-metal, sirolimus, or paclitaxel stent implantation. J Am Coll Cardiol. 2005;45 947-953.

58. Wiviott SD, Braunwald E, Angiolillo DJ, et al; TRITON-TIMI 38 Investigators. Greater clinical benefit of more intensive oral antiplatelet therapy with prasugrel in patients with diabetes mellitus in the trial to assess improvement in therapeutic outcomes by optimizing platelet inhibition with prasugrel - Thrombolysis in Myocardial Infarction 38. Circulation. 2008;118:1626-1636.

59. Kimura T, Morimoto T, Kozuma K, et al. Comparisons of baseline demographics, clinical presentation, and long-term outcome among patients with early, late, and very late stent thrombosis of sirolimus-eluting stents: observations from the Registry of Stent Thrombosis for Review and Reevaluation. (RESTART). Circulation. 2010;122:52-61.
60. Dangas GD, Caixeta A, Mehran R, et al; Harmonizing Outcomes With Revascularization and Stents in Acute Myocardial Infarction (HORIZONS-AMI) Trial Investigators. Frequency and predictors of stent thrombosis after percutaneous coronary intervention in acute myocardial infarction. Circulation. 2011;123:1745-1756.

61. Morice MC, Serruys PW, Sousa JE, et al. A randomized comparison of a sirolimus-eluting stent with a standard stent for coronary revascularization. $N$ Engl J Med. 2002;346:1773-1780.

62. Holmes DR Jr, Leon MB, Moses JW, et al. Analysis of 1-year clinical outcomes in the SIRIUS trial: a randomized trial of a sirolimus-eluting stent versus a standard stent in patients at high risk for coronary restenosis. Circulation. 2004;109:634-640.

63. Weisz G, Leon MB, Holmes DR Jr, et al. Five-year follow-up after sirolimus-eluting stent implantation: results of the SIRIUS (Sirolimus-Eluting Stent in De-Novo Native Coronary Lesions) trial. J Am Coll Cardiol. 2009;53:1488-1497.

64. Stone GW, Midei M, Newman W, et al. Comparison of an everolimuseluting stent and a paclitaxel-eluting stent in patients with coronary artery disease: a randomized trial. JAMA. 2008;299:1903-1913.

65. Costa RA, Lansky AJ, Mintz GS, et al. Angiographic results of the first human experience with everolimus-eluting stents for the treatment of coronary lesions (the FUTURE I trial). Am J Cardiol. 2005;95: 113-116.

66. Serruys PW, Ong AT, Piek JJ, et al. A randomized comparison of a durable polymer everolimus-eluting stent with a bare metal coronary stent: The SPIRIT first trial. EuroIntervention. 2005;1:58-65.

67. Stone GW, Rizvi A, Newman W, et al. Everolimus-eluting versus paclitaxel-eluting stents in coronary artery disease. $N$ Engl J Med. 2010;362:1663-1674.

68. Kedhi E, Joesoef KS, McFadden E, et al. Second-generation everolimuseluting and paclitaxel-eluting stents in real-life practice (COMPARE): a randomised trial. Lancet. 2010;375:201-209.

69. Schampaert E, Cohen EA, Schluter M, et al. The Canadian study of the sirolimus-eluting stent in the treatment of patients with long de novo lesions in small native coronary arteries (C-SIRIUS). J Am Coll Cardiol. 2004;43:1110-1115.

70. Grube E, Silber S, Hauptmann KE, et al. TAXUS I. Six- and twelve-month results from a randomized, double-blind trial on a slowrelease paclitaxel-eluting stent for de novo coronary lesions. Circulation. 2003;107:38-42.

71. Silber S, Colombo A, Banning AP, et al. Final 5-year results of the TAXUS II trial: a randomized study to assess the effectiveness of slow- and moderate-release polymer-based paclitaxel-eluting stents for de novo coronary artery lesions. Circulation. 2009;120:1498-1504.

72. Ellis SG, Stone GW, Cox DA, et al. Long-term safety and efficacy with paclitaxel-eluting stents: 5-year final results of the TAXUS IV clinical trial (TAXUS IV-SR: Treatment of de novo coronary disease using a single paclitaxel-eluting stent). JACC Cardiovasc Interv. 2009;2:1248-1259.

73. Ellis SG, O'Shaughnessy CD, Martin SL, et al; TAXUS V ISR Investigators. Two-year clinical outcomes after paclitaxel-eluting stent or brachytherapy treatment for bare metal stent restenosis: the TAXUS V ISR trial. Eur Heart J. 2008;29:1625-1634.

74. Burzotta F, Parma A, Pristipino C, et al. Angiographic and clinical outcome of invasively managed patients with thrombosed coronary bare metal or drug-eluting stents: the OPTIMIST study. Eur Heart J. 2008;29:3011-3021.

75. Aoki J, Lansky AJ, Mehran R, et al. Early stent thrombosis in patients with acute coronary syndromes treated with drug-eluting and bare metal stents: the Acute Catheterization and Urgent Intervention Triage Strategy trial. Circulation. 2009;119:687-698.

76. Stone GW, Lansky AJ, Pocock SJ, et al; HORIZONS-AMI Trial Investigators. Paclitaxel-eluting stents versus bare-metal stents in acute myocardial infarction. N Engl J Med. 2009;360:1946-1959.

77. Mauri L, Silbaugh TS, Garg P, et al. Drug-eluting or bare-metal stents for acute myocardial infarction. N Engl J Med. 2008;359:1330-1342. 
78. Sarno G, Lagerqvist B, Nilsson J, et al. Stent thrombosis in new-generation drug-eluting stents in patients with STEMI undergoing primary PCI: a report from SCAAR. J Am Coll Cardiol. 2014;64: 16-24.

79. Chieffo A, Bonizzoni E, Orlic D, et al. Intraprocedural stent thrombosis during implantation of sirolimus-eluting stents. Circulation. 2004;109:2732-2736.

80. Biondi-Zoccai GG, Sangiorgi GM, Chieffo A, et al. Validation of predictors of intraprocedural stent thrombosis in the drug-eluting stent era. Am J Cardiol. 2005;95:1466-1468.

81. Xu Y, Qu X, Fang W, Chen H. Prevalence, correlation and clinical outcome of intra-procedural stent thrombosis in patients undergoing primary percutaneous coronary intervention for acute coronary syndrome. J Interv Cardiol. 2013;26:215-220.

82. Brener SJ, Cristea E, Kirtane AJ, et al. Intra-procedural stent thrombosis: a new risk factor for adverse outcomes in patients undergoing percutaneous coronary intervention for acute coronary syndromes. JACC Cardiovasc Interv. 2013;6:36-43.

83. Généreux P, Stone GW, Harrington RA, et al. Impact of intraprocedural stent thrombosis during percutaneous coronary intervention: insights from the CHAMPION PHOENIX trial (clinical trial comparing cangrelor to clopidogrel standard of care therapy in subjects who require percutaneous coronary intervention). J Am Coll Cardiol. 2014;63: 619-629.
84. Nylander S, Asztély A. Reversal of ticagrelor-induced inhibition of ADP-induced platelet aggregation by the addition of uninhibited platelets in vitro. J Am Coll Cardiol. 2013; 61(10S):60215-60216.

85. Bonadei I, Sciatti E, Vizzardi E, D’Aloia A, Raddino R, Metra M. New frontiers in the management of acute coronary syndromes: cangrelor and elinogrel. Recent Pat Cardiovasc Drug Discov. June 10, 2014. [Epub ahead of print.]

86. Serebruany VL, Sibbing D, DiNicolantonio JJ. Dyspnea and reversibility of antiplatelet agents: ticagrelor, elinogrel, cangrelor, and beyond. Cardiology. 2014;127:20-24.

87. Yang W, Wang Y, Lai A, et al. Discovery of 4-aryl-7-hydroxyindolinebased p2y1 antagonists as novel antiplatelet agents. J Med Chem. 2014;57:6150-6164.

88. Delesque-Touchard N, Pflieger AM, Bonnet-Lignon S, et al. SAR216471, an alternative to the use of currently available P2Y12 receptor inhibitors? Thromb Res. 2014;134:693-703.

89. Dangas GD, Claessen BE, Mehran R, et al. Development and validation of a stent thrombosis risk score in patients with acute coronary syndromes. JACC Cardiovasc Interv. 2012;5:1097-1105.

90. Waksman R, Barbash IM. The appropriate use of risk score. JACC Cardiovasc Interv. 2012;5:1106-1107.
Vascular Health and Risk Management

\section{Publish your work in this journal}

Vascular Health and Risk Management is an international, peerreviewed journal of therapeutics and risk management, focusing on concise rapid reporting of clinical studies on the processes involved in the maintenance of vascular health; the monitoring, prevention and treatment of vascular disease and its sequelae; and the involvement of

\section{Dovepress}

metabolic disorders, particularly diabetes. This journal is indexed on PubMed Central and MedLine. The manuscript management system is completely online and includes a very quick and fair peer-review system, which is all easy to use. Visit http://www.dovepress.com/ testimonials.php to read real quotes from published authors. 